\title{
Testosterone levels of children with a diagnosis of developmental stuttering
}

\author{
This article was published in the following Dove Press journal: \\ Therapeutics and Clinical Risk Management \\ 14 May 2015 \\ Number of times this article has been viewed
}

\author{
Engin Burak Selçuk' \\ Lale Gönenir Erbay ${ }^{2}$ \\ Özlem Özel Özcan ${ }^{3}$ \\ Șükrü Kartalcı² \\ Kadir Batcıoğlu ${ }^{4}$ \\ 'Department of Family \\ Medicine, ${ }^{2}$ Department of Psychiatry, \\ ${ }^{3}$ Department of Child and Adolescent \\ Psychiatry, Inonu University Medical \\ Faculty, ${ }^{4}$ Inonu University Pharmacy \\ Faculty, Malatya, Turkey
}

Background: Stuttering is defined as a disruption in the rhythm of speech and language articulation, where the subject knows what he/she wants to say, but is unable to utter the intended word or phrase fluently. The effect of sex on development and chronicity of stuttering is well known; it is more common and chronic in males. We aimed to investigate the relationship between developmental stuttering and serum testosterone levels in this study.

Materials and methods: In this study, we evaluated a total of 50 children (7-12 years of age); eight (16\%) were female and 42 (84\%) were male. Twenty-five children who stutter and 25 typically fluent peers with the same demographic properties (ages between 7 years and 12 years) were included in this study. The testosterone levels of the two groups were determined in terms of nanogram per milliliter $(\mathrm{ng} / \mathrm{mL})$ by enzyme-linked immunosorbent assay. The difference between the means of the two groups was analyzed.

Results: The medians of the testosterone levels of the stutterer and control groups were determined as $20 \mathrm{ng} / \mathrm{mL}$ (range $=12-184 \mathrm{ng} / \mathrm{mL}$ ) and $5 \mathrm{ng} / \mathrm{mL}$ (range $=2-30 \mathrm{ng} / \mathrm{mL}$ ), respectively. Testosterone levels of the stutterer group were significantly higher than in the control group $(P=0.001)$. Besides, there was a significant correlation between the severity of the stuttering and testosterone levels in the stutterer group $(P=0.0001)$.

Conclusion: The findings of this study show that testosterone may have an effect on the severity of developmental stuttering and on the clinical differences between sexes. However, further investigations are needed to show that testosterone may play a role in the etiology of developmental stuttering.

Keywords: children, stuttering, testosterone

\section{Introduction}

Stuttering is a multifactorial speech disorder characterized by the extension of words, syllables, repeats, and blocks. While the exact etiology is unknown, genetic, neurophysiologic, and psychological factors are thought to play a role in various ways and combinations during development. ${ }^{1-3}$ There are two types of stuttering: developmental and acquired. Acquired stuttering may be neurogenic, psychogenic, pharmacogenic, or iatrogenic in origin. ${ }^{4}$ Developmental stuttering is seen in childhood and can continue until adulthood and is the most common form of stuttering. The female to male ratio varies with age in developmental stuttering.

Stuttering usually begins between the ages of 2 and 7 years and it is seen more commonly (ie, it is twice as likely) in boys in this age group, while the ratio changes during adulthood (it becomes up to five times more common in males). ${ }^{5,6}$ It is not fully known why stuttering is more common in males, and why it increases in prevalence among males in adulthood. The sex hormones, including androgens, may be considered to play a role as etiologic factors.
Correspondence: Engin Burak Selçuk Department of Family Medicine, Inonu University Medical Faculty, 44325, Malatya, Turkey

Tel +9042234 I 0660 Ext 5430

Fax +90 422 34I 0728

Email drenginselcuk@hotmail.com 
Androgens have various effects on the human brain and behavior. ${ }^{7,8}$ Testosterone is one of the most powerful androgens secreted from the testis and adrenal gland. It is known that testosterone plays a role in sexual activity, libido, social behaviors, aggression, cognitive functions, sleep regulation, and well-being in both males and females. ${ }^{9-12}$ There are studies supporting that testosterone may play a role in the etiologic factors of psychiatric disorders that have different prevalence rates based on sex, such as depression, psychosis, and anxiety disorders. ${ }^{13,14}$

On the other hand, being exposed to high levels of androgens in the early stages of neural development has been proposed to be associated with neurodevelopmental disorders, such as autism spectrum disorders and Tourette syndrome (TS), which affect the basal ganglia. ${ }^{15,16}$ It can be concluded that being exposed to high levels of androgens in the early stages of neural development has been proposed to be associated with stuttering. However, studies associated with this relationship to stuttering are quite limited. We have previously published about a 14-year-old boy who had no prior speech disorder, but whose stuttering symptoms had emerged after an injection of testosterone for hypogonadism, and which had intensified after the second dose. ${ }^{17}$

As a result, when the sex differences in the prevalence of stuttering, the effects of testosterone on the brain, and the case that we have published previously are considered together, we should ask the following question: "Is testosterone an etiologic factor of stuttering?" As such, we planned to investigate this possible etiologic relationship between developmental stuttering and testosterone levels. We wonder whether high serum testosterone levels are related with stuttering in terms of both etiology and chronicity.

\section{Materials and methods Subjects}

In this study, we evaluated a total of 50 children 7-12 years of age; eight (16\%) were female, $42(84 \%)$ were male. Twenty-five children between 7 and 12 years of age with a diagnosis of stuttering made between the years 2012 and 2014 at the Department of Child and Adolescent Psychiatry, Inonu University Medical School (Malatya, Turkey) and 25 typically fluent peers with similar demographic properties were included in the study. The study was approved by Ethics Committee of Inonu University, and written informed consent was obtained from the parents of the participants.

The children with stuttering were diagnosed by an experienced child and adolescent psychiatrist, using the Diagnostic and Statistical Manual of Mental Disorders, Fourth Edition
(DSM-IV) criteria. ${ }^{1}$ Children with concomitant psychiatric disorders (such as attention deficit/hyperactivity disorder, major depressive disorder, and social anxiety disorder); neurological, endocrine, or chronic disease; and a history of drug use were excluded from the study.

Physical examinations of the children in the stutterer and control groups were made by a family physician. Tanner staging, which is used to evaluate child development, was applied. ${ }^{18,19}$ Children who were in development stage 1 according to the Tanner staging were considered to be at the beginning of puberty and were thus excluded from the study.

The Clinical Global Impression-Severity Scale (CGI-S) is a clinical evaluation tool that can be used to determine many psychiatric disorders. ${ }^{20}$ This scale is a commonly used measure of symptom severity, treatment response, and the efficacy of treatments in treatment studies of patients with mental disorders. Grading of the scale pertains to disease severity: $1=$ normal, not at all ill; $2=$ borderline mentally ill; $3=$ mildly ill; $4=$ moderately ill; $5=$ markedly ill; $6=$ =everely ill; $7=$ =among the most extremely ill patients. ${ }^{20}$ In the evaluation of stuttering severity, each patient was asked to read the same storybook and to talk for 5 minutes about the same picture. All the stages were videotaped. An experienced child and adolescent psychiatrist assessed the children in terms of frequency, duration, physical concomitants, and naturalness of speech.

In our study, venous blood samples were collected at 9 am under sterile conditions. The samples that were obtained after the blood collection were centrifuged and stored in polypropylene tubes at $-80^{\circ} \mathrm{C}$.

\section{Serological techniques}

All biochemical analyses were performed in the Research Laboratory, Division of Biochemistry, Faculty of Medicine, Inonu University. A highly sensitive and specific commercial enzyme-linked immunosorbent assay kit (DK0002; DiaMetra $\mathrm{Srl}$, Milan, Italy) was used for the evaluation of testosterone in serum samples. The kit principle, based on the combination of testosterone in serum with horseradish peroxidase testosterone for binding, limited the number of antitestosterone sites on the microplate. Twenty-five microliters of five different known concentrations of testosterone standards and serum samples were added to standard and sample wells, respectively. Thereafter, $100 \mu \mathrm{L}$ of testosterone conjugate was added, mixed, and incubated at $37^{\circ} \mathrm{C}$ for 1 hour. Following the incubation, the content of each well was removed and washed twice with $300 \mu \mathrm{L}$ of distilled water. After washing, $100 \mu \mathrm{L}$ of tetramethylbenzidine substrate was added to each well and incubated at room temperature for 15 minutes in the 
dark. By the addition of $100 \mu \mathrm{L}$ of stop solution to each well, the reaction was stopped. The amount of testosterone in the serum samples was determined by measuring optical density at $450 \mathrm{~nm}$ on a multimode microplate reader (BioTek Synergy ${ }^{\mathrm{TM}}$ H1M; BioTek Instruments, Inc., Winooski, VT, USA). The testosterone concentration was calculated from the standard calibration curve. All results were expressed as ng/mL.

\section{Statistical analysis}

Statistical analyses were performed with the SPSS for Windows version 17.0 program. All data were reported as the mean \pm standard deviation. Normality for continuous variables (testosterone levels, age) in the groups was determined by the Shapiro-Wilk test. The variables did not show a normal distribution $(P<0.05)$, so the Mann-Whitney $U$-test was used to compare variables between the studied groups. The correlation of stuttering severity in children with the plasma levels of total testosterone was analyzed by Pearson's correlation test. The testosterone values in the control, mild, and severe disease groups were analyzed with the analysis of variance test. A value of $P<0.05$ was considered significant.

\section{Results}

In this study, we evaluated a total of 50 children (7-12 years of age) who had not yet entered into puberty. There were four $(16 \%)$ female and 21 (84\%) male children whose average age was $9.5 \pm 1.9$ years in the stutterer group; the same number of males and females were in the control group, and their average age was $9.5 \pm 1.8$ years. There was no significant difference between the stutterer and the control groups in terms of age and $\operatorname{sex}\left(t=0.21, P>0.05 ; \chi^{2}=0.082\right.$, $P>0.05$, respectively).

In the descriptive analysis, a normal distribution of the groups was not shown, so the Mann-Whitney $U$-test was used to determine whether any differences were noted among the stutterer and control groups in terms of testosterone levels.

The medians of the testosterone levels of the stutterer and control groups were determined as $20 \mathrm{ng} / \mathrm{mL}$ (range $=12-184 \mathrm{ng} / \mathrm{mL}$ ) and $5 \mathrm{ng} / \mathrm{mL}($ range $=2-30 \mathrm{ng} / \mathrm{mL}$ ), respectively. The testosterone level of the stutterer group was significantly higher than that of the control group $(P=0.001)$.

CGI-S disease severity values and their relationship with testosterone levels were assessed with Pearson's correlation analysis in the stutterer group. The analysis revealed a positive correlation between disease severity and testosterone levels $(r=0.75, P=0.0001)$.

According to the CGI-S score, children's stuttering was divided into one of two stuttering level groups: $1-4$ points as mild-to-moderate stuttering and 5 or more points as severe stuttering. The median values of testosterone levels in the mild-to-moderate group, severe group, and control group were determined as $20 \mathrm{ng} / \mathrm{mL}$ (range $=12.00-95.00 \mathrm{ng} / \mathrm{mL}$ ), $88 \mathrm{ng}$ / $\mathrm{mL}$ (range $=33-184 \mathrm{ng} / \mathrm{mL}$ ), and $5 \mathrm{ng} / \mathrm{mL}$ (range $=2-30 \mathrm{ng}$ / $\mathrm{mL})$, respectively.

The difference between the testosterone levels of the mild-to-moderate, severe, and control groups was examined with the Mann-Whitney $U$-test, and the three groups were significantly different in terms of testosterone levels $(P=0.0001)$. There were no significant differences between the groups in terms of age and sex $(P>0.05$ and $P>0.05$ respectively) (Table 1).

\section{Discussion}

As far as we know, this study is the first to evaluate testosterone levels in a group of children with pediatric stuttering. The main findings of our study were that the testosterone levels in children with stuttering were significantly higher when compared to those of the typically fluent peer group; this also showed a positive correlation with disease severity.

Stuttering usually begins between the ages of 2 and 7 years, and it is seen two times more frequently in boys in this age group, while the ratio changes in the adult age group, occurring up to five times more in the male sex..$^{1,2}$

It is not fully known why stuttering is common in males and why it is uncommon in females in adult age groups. Given the differences between the sexes, it can be considered that testosterone, which is a sex hormone, might play a role

Table I Sociodemographic features and testosterone levels of the stutterer and control groups

\begin{tabular}{llll}
\hline Demographic data & Stutterer group $\mathbf{n}=\mathbf{2 5}$ & Control group $\mathbf{n}=\mathbf{2 5}$ (mean \pm SD) & Comparison \\
\hline Age & $9.5 \pm 1.9$ & $9.6 \pm 1.8$ & $t=0.21$ \\
Sex & & & $P>0.05$ \\
$\quad$ Male & $84 \%$ & $84 \%$ & $\chi^{2}=0.082$ \\
$\quad$ Female & $16 \%$ & $16 \%$ & $P>0.05$ \\
Testosterone level $(\mathrm{ng} / \mathrm{mL})(\min -\mathrm{max})$ & $20(12-184)$ & $5(2-30)$ & $P=0.001$ \\
\hline
\end{tabular}

Abbreviations: $n$, number of subjects; SD, standard deviation. 
in the etiology and chronicity of the disease. The results of this study show that serum testosterone levels are associated with the severity of stuttering. We have previously mentioned our paper about a 14-year-old boy who had no prior speech disorder, but whose stuttering symptoms had emerged after an injection of testosterone for hypogonadism, and which had intensified after the second dose. ${ }^{17}$ Considering these two findings together, we may conclude that testosterone might play an etiologic role in stuttering.

According to the theory of cerebral dominance, the left hemisphere of the brain is more active in fluent-speaking subjects and during speech-related activities. ${ }^{21}$ It has been reported that the left half of the brain, which provides quick signal transitions during a conversation, is not dominant enough in children with stuttering. ${ }^{22}$ It was proposed that boys who were exposed to high testosterone levels during the fetal period may have delays in the development of the left hemisphere, and so the right brain hemisphere becomes more active, which leads to stuttering. ${ }^{23}$ Differences in hemispheric dominance may be implicated as causes in stuttering, autism, and dyslexia, which are seen in high prevalence rates in the male sex. ${ }^{24}$

In addition to the cerebral dominance theory, the basal ganglia-thalamocortical motor circuits may play a key role in stuttering, with contributions from the putamen. ${ }^{25}$ It was shown that acquired stuttering is the result of a lesion in this circuit, and that the primary speech and language centers (Broca's area, the planum temporale, the insula, and Wernicke's area) are not affected. ${ }^{26}$ Studies have proposed that stuttering may be associated with disorders related to the basal ganglia, which is a network that deals with structural motor control. The basal ganglia play an important role in motor behavior, emotions, and cognition. Depending on the common etiology of stuttering and movement disorders (Parkinson, TS, dystonia, etc), such as a lesion in the basal ganglia-thalamocortical circuit, it can be thought that they may have other common properties. Indeed, children with stuttering have been found to exhibit an increase in abnormal facial movements during talking, but that are not directly linked to talking. ${ }^{27,28}$

A relationship was found between some disorders and the level of dopamine elevation, such as attention deficit hyperactivity disorder, obsessive-compulsive disorder, and tic disorders. ${ }^{29,30}$ Similarly, it has been suggested that an increase in the activity of the dopamine-producing neurotransmitter system may cause stuttering. ${ }^{31}$ In the same way, in stuttering children, it has been shown that there is an improvement in fluency with the use of an antidopaminergic agent. $^{32,33}$ Testosterone regulates cell death and dopamine transport in the substantia nigra and striatum. ${ }^{34}$ It has been shown that changes occurring in the sex steroids during adolescence play an important role in dopamine signaling and regulation. ${ }^{35}$ Testosterone may impact upon the disease in this way. Indeed, the role of testosterone in the diseases where dopamine and the basal ganglia play important roles (Parkinson's, TS, dystonia, etc) have been studied. Specifically, sex differences and the role of testosterone on these diseases were investigated. ${ }^{36}$ It was found that giving exogenous androgen can aggravate tics in males with TS. Some drugs that have antitestosterone effects also have antitic effects. This shows that the patients with TS have a high level of sensitivity to androgen steroids. ${ }^{37}$

Fetal testosterone affects cerebral dominance, and it also plays an important role in the etiology of stuttering; however, the data in the literature are limited with respect to postnatal testosterone levels in the development of stuttering and their effects on the severity or chronicity of the disease. ${ }^{23}$ Depending on the knowledge about how speech-related structures in the brain are affected by testosterone, ${ }^{23,38}$ and based on our finding of high testosterone levels in stuttering subjects (which is a speech and language disorder), it can be thought that there may be a relationship between postpartum testosterone levels and stuttering. When our findings in this study and the case we presented previously are taken into account together, it can be concluded that in the postnatal period, testosterone may have an effect on the emergence, course, and severity of stuttering. ${ }^{17}$

However, from a different point of view, high testosterone levels may not be the cause of stuttering, but it may be a result of stuttering. The role of stress on the triggering of stuttering is well known. ${ }^{39}$ Stress factors play a particular role in the triggering of acquired stuttering; also, stuttering is a stress factor in itself, so this vicious cycle has been reported to lead to chronicity in stuttering. ${ }^{1,2}$ Stress activates the hypothalamo-pituitary-adrenal (HPA) axis and, consequently, a hormonal axis that includes testosterone (HPA) is activated by stress. ${ }^{40,41}$ Thus, the stress that arises during stuttering activates the HPA axis and it can be concluded that serum testosterone levels can increase during stuttering.

All these may be evaluated, as stuttering is not only a speech disorder, but it can also be considered as a motor disorder. Stuttering may be evaluated within a wider category (such as movement disorders) that involves Parkinson's disease, TS, and tic disorder, depending on their similarities, which include a high male incidence rate, a testosterone-dopamine 
interaction in its etiology, and the importance of the basal ganglia-thalamocortical motor circuits.

These are the results of the first study to assess whether testosterone may play a role in the formation of stuttering; however, this relationship cannot be fully elucidated. One of the main reasons for this, and the main limitations of this study, is the low subject number. In order to clarify the relationship between testosterone and stuttering, men and women should be evaluated separately. Moreover, studies should include more subjects, and longitudinal studies may need to be performed.

\section{Conclusion}

Based on the results of this study, it may be concluded that testosterone might play a role in the etiology and chronicity of stuttering; however, this relationship has not been fully revealed. One of the main reasons for this is that the number of children with stuttering included in this study was not high enough to draw this conclusion. Further progressive studies that involve both sexes in high numbers will be important to discover the exact relationship between testosterone and stuttering.

\section{Disclosure}

The authors report no conflicts of interest in this work.

\section{References}

1. American Psychiatric Disorder. Stuttering. In: Diagnostic and Statistical Manual of Mental Disorders (DSM-IV). 4th ed. Washington, DC: American Psychiatric Association; 1994:63-65.

2. Prasse JE, Kikano GE. Stuttering: an overview. Am Fam Physician. 2008;77(9):1271-1276.

3. Özcan Ö, Altınayar S, Özcan C, Ünal S, Karlıdag R. P50 sensory gating in children and adolescents with developmental stuttering. Klinik Psikofarmakol Bülteni. 2009;19(3):241-246.

4. Boyd A, Dworzynski K, Howell P. Pharmacological agents for developmental stuttering in children and adolescents: a systematic review. J Clin Psychopharmacol. 2011;31(6):740-744.

5. Yairi E, Ambrose NG. Early childhood stuttering I: persistency and recovery rates. J Speech Lang Hear Res. 1999;42(5):1097-1112.

6. Ambrose NG, Cox NJ, Yairi E. The genetic basis of persistence and recovery in stuttering. J Speech Lang Hear Res. 1997;40(3): 567-580.

7. Morley JE. Testosterone and behavior. Clin Geriatr Med. 2003;19(3): 605-616.

8. Höfer P, Lanzenberger R, Kasper S. Testosterone in the brain: neuroimaging findings and the potential role for neuropsychopharmacology. Eur Neuropsychopharmacol. 2013;23(2):79-88.

9. Seidman SN. Testosterone deficiency and mood in aging men: pathogenic and therapeutic interactions. World J Biol Psychiatry. 2003; 4(1):14-20.

10. Steiner M, Dunn E, Born L. Hormones and mood: from menarche to menopause and beyond. J Affect Disord. 2003;74(1):67-83.

11. Zitzmann M. Testosterone and the brain. Aging Male. 2006;9(4): 195-199.

12. Barrett-Connor E, Goodman-Gruen D, Patay B. Endogenous sex hormones and cognitive function in older men. J Clin Endocrinol Metab. 1999;84(10):3681-3685.
13. Howard JM. Testosterone and psychosis. Br J Psychiatry. 2004; $185: 173$.

14. Kartalcı Ş. Testosterone and depression. Current Approaches Psychiatry. 2010;2(4):457-472.

15. Baron-Cohen S, Auyeung B, Nørgaard-Pedersen B, et al. Elevated fetal steroidogenic activity in autism. Mol Psychiatry. 2015;20(3): 369-376.

16. Martino D, Macerollo A, Leckman JF. Neuroendocrine aspects of Tourette syndrome. Int Rev Neurobiol. 2013;112:239-279.

17. Kartalcı Ş, Erbay LG, Özcan ÖÖ, Yüksel T, Ünal S. Stuttering after testosterone administration: a case report. Anadolu Psikiyatri Dergisi. 2012;13(1):82-84

18. Marshall WA, Tanner JM. Variations in the pattern of pubertal changes in boys. Arch Dis Child. 1970;45(239):13-23.

19. Marshall WA, Tanner JM. Variations in pattern of pubertal changes in girls. Arch Dis Child. 1969;44(235):291-303.

20. Busner J, Targum SD. The clinical global impressions scale: applying a research tool in clinical practice. Psychiatry (Edgmont). 2007; 4(7):28-37.

21. Fleet WS, Heilman KM. Acquired stuttering from a right hemisphere lesion in a right-hander. Neurology. 1985;35(9):1343-1346.

22. Andrews G, Craig A, Feyer AM, Hoddinott S, Howie P, Neilson M. Stuttering: a review of research findings and theories circa 1982. J Speech Hear Disord. 1983;48(3):226-246.

23. Geschwind N, Galaburda AM. Cerebral lateralization. Biological mechanisms, associations, and pathology: III. A hypothesis and a program for research. Arch Neurol. 1985;42(7):634-654.

24. Bloodstein O. Stuttering: The Search for a Cause and Cure: Boston, MA: Allyn \& Bacon; 1993.

25. Alm PA. Stuttering and the basal ganglia circuits: a critical review of possible relations. J Commun Disord. 2004;37(4):325-369.

26. Ludlow CL, Loucks T. Stuttering: a dynamic motor control disorder. J Fluency Disord. 2003;28(4):273-295; quiz 295.

27. Conture EG, Kelly EM. Young stutterers' nonspeech behaviors during stuttering. J Speech Hear Res. 1991;34(5):1041-1056.

28. Mulligan HF, Anderson TJ, Jones RD, Williams MJ, Donaldson IM. Tics and developmental stuttering. Parkinsonism Relat Disord. 2003;9(5):281-289.

29. Tibbo P, Warneke L. Obsessive-compulsive disorder in schizophrenia: epidemiologic and biologic overlap. J Psychiatry Neurosci. 1999; 24(1):15-24.

30. Leckman JF, Peterson BS, Pauls DL, Cohen DJ. Tic disorders. Psychiatr Clin North Am. 1997;20(4):839-861.

31. Healey EC. Readings on Research in Stuttering. New York, NY: Longman; 1991.

32. Lavid N, Franklin DL, Maguire GA. Management of child and adolescent stuttering with olanzapine: three case reports. Ann Clin Psychiatry. 1999;11(4):233-236.

33. Maguire GA, Riley GD, Franklin DL, Gottschalk LA. Risperidone for the treatment of stuttering. J Clin Psychopharmacol. 2000;20(4): 479-482.

34. Di Paolo T. Modulation of brain dopamine transmission by sex steroids. Rev Neurosci. 1994;5(1):27-41.

35. Sinclair D, Purves-Tyson TD, Allen KM, Weickert CS. Impacts of stress and sex hormones on dopamine neurotransmission in the adolescent brain. Psychopharmacology (Berl). 2014;231(8):1581-1599.

36. Smith KM, Dahodwala N. Sex differences in Parkinson's disease and other movement disorders. Exp Neurol. 2014;259:44-56.

37. Leckman JF, Scahill L. Possible exacerbation of tics by androgenic steroids. N Engl J Med. 1990;322:1674.

38. Wisniewski AB. Sexually-dimorphic patterns of cortical asymmetry, and the role for sex steroid hormones in determining cortical patterns of lateralization. Psychoneuroendocrinology. 1998;23(5): 519-547.

39. Ezrati-Vinacour R, Levin I. The relationship between anxiety and stuttering: a multidimensional approach. J Fluency Disord. 2004;29(2): $135-148$. 
40. Kartalcı Ş, Eşel E. Psychopharmacologic and behavioral effects of neurosteroids. Klinik Psikofarmakoloji Bülteni. 2004;14(1): $38-49$.
41. Volman I, Toni I, Verhagen L, Roelofs K. Endogenous testosterone modulates prefrontal-amygdala connectivity during social emotional behavior. Cereb Cortex. 2011;21(10):2282-2290.

\section{Publish your work in this journal}

Therapeutics and Clinical Risk Management is an international, peerreviewed journal of clinical therapeutics and risk management, focusing on concise rapid reporting of clinical studies in all therapeutic areas, outcomes, safety, and programs for the effective, safe, and sustained use of medicines. This journal is indexed on PubMed Central, CAS,
EMBase, Scopus and the Elsevier Bibliographic databases. The manuscript management system is completely online and includes a very quick and fair peer-review system, which is all easy to use. Visit http://www.dovepress.com/testimonials.php to read real quotes from published authors. 